factory, because our knowledge on that subject is the most complete, and, as our colleague Mr. Hilton has abundantly proved, admits of some rationale. The physiologist has a harder and drier duty in pointing out the development of the organs and the combination of their functions into an organic whole, since if he lapse-as who can at all times help it?-into theories of the "Why", he weakens the directness of observation upon which you must build, if you build securely. Then comes the pathologist on the nature and course of disease, proving it to be mostly but a part of physiology. After these, therapeutics, happily much less encumbered than formerly with a farrago of nostrums, since pathology has taught us that the processes of disease have often a conservative tendency, and that frequently our duty is to do no more than prevent violent interference. When and how we can do more, it is the great object of therapeutics to point out. Of the study of the practice of medicine and surgery, every thing around you here speaks at all times and invites your attention. The several departments of the hospital afford the rarest opportunities for acquaintance with accidents and disease in all forms; and if a knowledge of the practical parts of your profession cannot be gained here, it may be certainly said it cannot be gained elsewhere.

I look back with pleasure to the time when I had no world but the wards of this hospital, and often regret I am now so separated from them. All the success I have had springs from Guy's, and here are my early and best associations. I cannot, therefore, but feel as one of yourselves. I could wish it were again my lot to work with you, but the time is passed, and younger and stronger hands will direct you, whilst it only remains for me to cordially wish you success.

Mr. Treasurer, I cannot close this address without publicly acknowledging the great debt which our hospital and school owe to your able and devoted services. I know that you and the governors are deeply convinced that the prosperity of the two are intimately connected. My colleagues equally feel this to be so, and, speaking for them, I may confidently assure you that their best energies will be devoted to both.

\section{INTRODUCTORY ADDRESS}

\section{THE DUTIES AND RESPONSIBILITIES OF THE MEDICAL STUDENT.}

Delivered at the Leeds School of Medicine, October Ist, 1874.

\section{By C. G. WHEELHOUSE, F.R.C.S.,} Senior Surgeon to the Hospital.

Gentlemen, - I have often heard the question asked, "Of what use is the Introductory Address?" In some schools, it has been declared to be of no use at all, and has accordingly been discontinued; but I should deeply regret such discontinuance in this school, not only on the ground that I consider the practice, notwithstanding the triteness, to many of us, of the tale that has to be told, to be a most wholesome one, but also because, on this occasion, it would deprive me of an opportunity which, while it imposes upon me a very responsible duty, gives me also very unmixed pleasure.

As I cast my eye over the many eager faces I see grouped around me, I cannot help looking back to this day twenty-eight years ago, when I myself, full of elation at the prospect opening up before me, took my seat as a student upon the benches of this school ; and I cannot forget how vividly I was looking forward to the fulfilment of hopes which, exen then, had taken very definite shape, and had rooted themselves deeply in my mind. When I remember with what eager anticipation I looked forward to the address which was to be my introduction to the real work of the great battle of life, and how I drank in every word of it, I cannot but rejoice that I am permitted once more to offer that welcome to you, and to speak to you those words of encouragement which shall stimulate your energies, and induce you to address yourselves to your coming labours with that sincerity and reverence which alone will enable you to triumph over the many and grave difficulties with which you will find your path beset.

The omission of such an address would, in my judgment, be a tie loosened, a link in the social chain of our professional life so weakened, as to leave the binding influence of that chain for good so much enfeebled, that the sympathy of the learner with the teacher would be no longer that which we have always striven to make it; it would strike a blow, in the very commencement of our labours, which would tend to lessen the harmony of our future relations the one with the other.

So, gentlemen, in my own name and in the names of my colleagues, I bid you heartily welcome. Those among you who are not joining us for the first time, we welcome to a renewal of studies which have only for a time been interrupted by the vacation, with an earnest hope that you are returning reinvigorated by rest, with heads freshened and cleared by repose, and ready once more to enter with alacrity and ardour upon duties which, when I last addressed you, had perhaps begun to become somewhat wearisome at the close of a long session.

And to those who are taking your places amongst us for the first time to-day, and who, by so joining us, are also taking the most important step of your whole lives, what am I to say? Not only that we bid you heartily welcome, not only that we hail you gladly as recruits who, when we ourselves shall fall out of the ranks, will be ready to step forward and occupy our places, but that I am charged with a message to you, the responsibility of which I find it impossible to overestimate. I am here to-day more especially to unfold to you some of the leading features of your new career, to stimulate your hopes and expectations with regard to it, and to ratify and confirm the wisdom of the choice you have made in entering upon it by declaring it to be amongst the very noblest of all noble occupations; dealing with the grandest conceptions which have ever entered either the heart or mind of man, and as one which, when pursued in the true spirit of philanthropy and single-heartedness, will suffice to fill your whole after-lives with a happy consciousness of devotion to the highest objects of which human nature is capable. To you hereafter will be given the alleviation of the woes and sufferings of those who are affected; the mitigation of the sharpness of the strokes of disease; the restoration of the sick to health ; and, above all, the tracking of disease, not only to its secret hiding-places, but to its very birth-place, that you may stamp it out before it has the opportunity to germinate and spread. High and noble duties, indeed, you will be tempted to say, but how are we to fit ourselves to undertake them? By strict attention, I would answer, to the curriculum laid down for you by the authorities, remembering that every point in that curriculum has been carefully thought out for you by those who know best how to direct your studies, and by following the advice of those under whose guidance you now place yourselves, and who will at all times be ready to help you to solve any difficulty that may spring up in your path.

Your first two years ought undoubtedly to be devoted to the three great studies upon which you will afterwards have to build up everything else; viz., Anatomy, Chemistry, and Physiology.

It is manifest that, without a complete, practical, and thorough knowledge of anatomy, you can never hope to become either physicians or surgeons ; and, seeing that disease consists mainly in either change of structure or in disordered physiological action, or both, it is no less clear that a profound knowledge of physiology, as well as of anatomy, is an essential part of the foundation you must lay. But, though you may have attained to the highest conceivable knowledge of the structure of the body, it will be simply impossible to attain to any perfect understanding of the functions and uses of its various organs, unless you have also acquired a good and sound insight into the main laws of chemistry and chemical action.

Physiology is in reality the chemistry of organic life in action. Every thought that scintillates from your brain is the result of chemical change; every throb that accompanies the action of your heart arises from the same ultimate source; and every breath you draw would fail in its purpose if it were not directly accompanied by vital chemical changes. Hence, to understand physiology, you must be well acquainted with the more ordinary phenomena and laws of chemistry, as well as with the structure of the organs whose actions you desire to study; and, as you become proficients in anatomy and chemistry, so will you be prepared to undertake the more complicated study of physiology, and to trace out not only the functions of individual organs, but also so to group them together as step by step to rise to the perception of the harmonies of the whole as they constitute the great facts of life and health. Here, then, is clearly marked out the first great object of your student career : a knowledge of the structure and of the working of the machine which it will be your great duty hereafter to regulate and keep in order.

And now let me say a word or two as to how these studies should be conducted.

At the close of the second year of your curriculum, it will be your duty to present yourselves before certain examiners, and your examination will, of course and of necessity, be looked upon as a momentous matter ; but, so far as you are able, I advise you to dismiss the thought of examination altogether from your minds. Work as if no such occasion were confronting you ; work as if your one and only object were the acquirement of knowledge, and the examination will come, not as a terrible moment of reckoning, but as an occasion on which you may with pardonable pride show how much you have acquired. The watch- 
maker, or the engineer, as he ponders over the mechanism of the watch or piece of machinery upon whose construction he is bent, has no such fear before his eyes. He carefully surveys every wheel and lever, valve and spring, thinking only of the perfection to which he hopes to be able to bring his work; and that is the spirit of inquiry I recommend for your adoption. Your machine is the human body; pick it to pieces, fibre by fibre, and over and over agrain, until there is no part of it whose structure you do not fully comprehend. Rely on your anatomic guidebooks only as, when you were schoolboys, you used to rely on your dictionaries and your lexicons; apply to them only when you are in a difficulty, and use them only as guides to that which you cannot understand without their help.

There is too great a tendency in the study of anatomy to rely more upon the help of the book than upon the "subject" itself, and, in times of trial, knowledge so acquired is very apt to fail. You may depend upon it, the ancient anatomists, who had no books but the book of nature, so pored over that one volume, that no thought of "examination" would have terrified them or made them nervous; and, when I hear of a man being so nervous at an examination, that he loses his self-confidence, I always feel inclined to attribute the failing to insecurity in the foundation on which his knowledge is based.

With regard to physiology, you must be more dependent upon reading than in the case of anatomy. It is a science which has only been slowly evolved, and which has grown to its present proportions only commensurately with the growth of collateral sciences, and chiefly with that of chemistry ; but it is the science upon which medicine is built, and unfortunately it is one which until lately has been considered to be more appropriately the possession of the professor than of the student. Of late years, however, a more and more thorough knowledge of the subject has been demanded by the authorities; and I think I am not wrong in saying that, of late years also, more and more candidates have been rejected for deficiency in this branch than in the more practical one of anatomy. I, therefore, very urgently commend it to your serious consideration, and would impress upon you the necessity of constituting it from the first amongst your principal and most earnest studies.

With these three suljjects, then-Anatomy, Chemistry, and Physiology-your time, during your two first winters' attendances, may be very fully occupied; so fully, that I do not advise you to enter, in any systematic sense, upon the more advanced subjects of "medicine" or "surgery" at first; these will come much more appropriately later on, and, with a good groundwork such as I have indicated, will be studied to much greater advantage.

And yet, even during your first year, you may be laying something of a foundation for their study also. You will need some change of thought and occupation, some mental recreation. Let that recreation be found in the wards of the hospital. The success of your after-career will depend greatly upon the degree to which you have educated two faculties innate in all our minds-the faculties of observation and imitation. These you cannot begin to cultivate too early, nor can you ever educate them too highly. Begin, then, from the very first ; spend a certain amount of every day in the hospital; watch everything that is done there by everybody; observe for yourselves everything that goes on. Observation is one of the highest faculties for good that you possess, and will do more for you than genius in its highest flights. Observation led Sir Isaac Newton to that greatest of all physical discoveries, the discovery of gravitation. No other power than that of patient observation could have led Harvey to the discovery of the circulation of the blood ; and observation, again, in the case of our immortal countryman Jenner, eventuated in that glorious discovery of vaccination, by which the direst scourge that ever afflicted the human race has been almost, and is capable of being perfectly, eradicated and stamped out of existence.

Observe, then, everything that goes on in the hospital around you, even though you may not in the least understand much of what you see a time will come, later on, when you will be abundantly repaid, and hours apparently inactively spent now will prove to have been the seed time from which a rich and abundant harvest will spring up hereafter. Watch every manipulation, whether medical or surgical, that you see ; imitate every one of them, until you are able to produce such results with them as you see to follow in the hands of others.

You will learn how the physician brings all his senses to bear upon every fresh case that is presented to his observation; you will see how he notes with his eye the wan and wasted aspect of a patient; how, by his senses of touch and hearing, he appreciates the condition of the circulation; how his hand has been educated to elicit, by palpation and percussion, the condition of internal organs; and, whenever you have the opportunity, imitate all you have seen him do; then think what each action has taught you ; your thorough appreciation of it all will come later on, but in the meantime you will be acquiring the rudi- ments of knowledge which, in later times, will be of great value to you.

In like manner, watch and, as far as you can, imitate all that you see the surgeon do; the application of ordinary dressings, bandages, and all kinds of surgical appliances; so that, when it comes to your turn in after time, they may not be altogether unfamiliar to you ; and so you will pick up, almost as a matter of recreation, information and handiness which, in the more advanced stages of your career, you will greatly rejoice that you possess. Sir Astley Cooper used to be in the habit of assuring his pupils that a man's hands, in the doing of little things, often did more to advance his reputation than did his head; and I can speak from personal observation that this, at all events, is very often so, and that, though a man may have a profound and scholarly knowledge of the pathology of internal diseases, he may mar all by the fact, that he is unable to use even simple instruments with facility and ease. All these minor operations you may watch over and over again as performed by others, until at last you will come consciously to feel that you could do them yourselves. Then, whenever an opportunity occurs, seize it with avidity, and never forget that it is practice, and practice only, that will give you that ease and facility of manipulation which, when it comes in aid of sound judgment, will bring you the inward consciousness of surgical superiority.

In this manner, you will most profitably spend the two first years of your studentship, and, short though that time may appear to you, it will suffice to give you such an insight into and knowledge of the subjects required for your primary examination, that you will pass through that ordeal, not only with satisfaction to yourselves, but with credit also to your school-a matter of which I trust you will never altogether lose sight.

This portion of your studentship over, a firm and solid foundation having been laid, the time will come when you will associate yourselves more closely with those whose duty it will be to aid you in raising the superstructure whose building is to be henceforward the labour of your lives. So long as you remain with us, we shall help you patiently to pile stone upon stone, until the edifice is simply raised. When it is so far completed as to be ready for occupation, you will leave us, and then will commence the time of the real trial of its strength. If its foundation have been laid in the sand, and its superstructure have been insecurely wrought, it will need but few of the buffetings and storms of real practical life to bring it with ignominy to the ground; but, if the work, so far as it has gone, be substantial, if the foundation have been laid in the rock, no matter how fiercely the winds may howl around it, it will stand unshaken by them, and year by year the artificer, proud of his work so far only because of its solidity and strength, will commence, with loving hand, to beautify and adorn it. Column and carving, turret and pinnacle, tracery, fretwork, and moulding, will be added as years roll on, until at last, when the mists of age begin to dim the eye, and its feebleness to paralyse the hand of the builder, he will lay aside his tools with conscious pride in his goodly work, and will hand it on to his successors, assured that he, at any rate, has not been an idle and unprofitable labourer, and that, though his hands may not have been permitted to conclude the work, they may at least have added new beauties to it, and have left it the comelier an edifice for his labours.

In the building of this structure, it will be our duty, as your teachers, more especially in the branches of Medicine, Surgery, and Midwifery, to give you every assistance that lies in our power, and you will find in the hospital abundant material upon which we may work together. Our province will be to explain, to expound, to guide ; yours to observe, to inquire, and to question for yourselves, never hesitating to come to us with your difficulties, or to ask for any information you may need to help you.

In the first instance you will find much that will appear to you to be inexplicable, and difficulty after difficulty will arise in your path, but by patient perseverance you will overcome all these. In the first instance, too, you will undoubtedly find much that will greatly distress you, and some things that will probably disgust you, but these will be amongst the first difficulties you will surmount, and all that is needed, so far as they are concerned, to enable you to do this will be steady perseverance, and a firm conviction of duty.

We must ask you to be very tender and forbearing with the sick, remembering that they are conscious sufferers, and are often placed under very trying and painful circumstances; to look with kindly gentleness upon many a caprice which you might otherwise be inclined to censure, remembering that they have need of every comfort and consolation we can afford them. They are the material upon which you have to work, and their diseases and distresses are your study. Ask yourselves, what are these diseases? and I will give you an appropriate answer in the beautiful and graphic words of Dr. Latham.

"They are not abstractions; they are modes of acting different from 
the natural and healthy modes; modes of disorganising; modes of suffering; and modes of dying; and there must be a living sentient body for all this. This body must be your study, and your continual care, your active, willing, earnest care. Nothing must make you shrink from it. In its weakness and infirmities; in the dishonours of its corruption, you must still value it, still stay by it ; to mark its hunger and thirst, its sleeping and waking; its heat, its cold ; to hear its complaints and to register its groans. And is it possible, you may ask, to feel an interest in all this ? Aye, indeed it is, a greater, far greater interest than ever painter or sculptor took in the form and beauties of its health. And whence comes this interest? At first, perhaps, it seldom comes naturally, a mere sense of duty must engender it ; and still, for a while, a mere sense of duty must keep it alive. Presently, the quick, curious, restless spirit of science enlivens it, and then it becomes an excitement, and then a pleasure, and then the deliberate choice of the mind."

'Thus medicine, surgery, and midwifery will come, in the latter part of your student life, to occupy your attention almost exclusively. If you have made yourselves thoroughly masters of the more preliminary branches of your education, you will never forget them; you will find yourselves making such constant reference to them, that they cannot escape from your memories; but you will only refer to them as guides and helps in your attempts to unravel the mysteries of disease and death, and as pointing your steps in the best directions in which to fight and conquer them, or lead them to a safe conclusion; and so, at length, you will become so absorbed in your work that you will forget its drudgery, and will learn to delight in it for itself alone.

Now, let me for a few moments try to inculcate what this feeling will be, by asking you to look back upon the steady advances that have been made in medical knowledge during the generation of which, for a moment, you may regard your teachers in this school as the representatives.

The study of anatomy is perhaps the most ancient of any that you will be called upon to undertake, and though many of the structures of the body are now better comprchended than they were fifty years ago, it is not because the structures themselves were not well known to our forefathers, but because we possess, if not one sense more than they did, at least one sense so infinitely intensified, that its power in our case is more than quadruple what it was in theirs. The microscope may be said to have been invented in 1820 , and, from that time onward to the present day, improvements in its construction have followed so rapidly one upon another that it seems now as if there were very little left to desire in the way of improvement. And what has the microscope done for us? It has unfolded the mysteries hidden in ten thousand pages in that section of the book of Nature which it is our province to study and elucidate. Whereas our fathers knew only the relative position and outward differences of structure of the various organs of the body, we can penetrate into the secrets of their very ultimate construction; and myriads of facts which could only be puzzles to them, are scientific facts, clear as daylight to us, and, read by the light of the bright illumination thrown on them by our now nearly perfect instruments, ccase almost to be marvellous in our eyes.

Even since I have held the honoured position of a teacher of physiology in this school, the facts added to our physiological knowledge by the aid of the microscope may fairly be called innumerable; and, as I read the brilliant address delivered only a few weeks ago by Professor Redfern, in the biological section of the British Association for the Advancement of Science at Belfast, and compared the state of the science now with what it was twenty years ago, I was constrained to think that no instrument of greater utility than the microscope, not even the locomotive or the electric telegraph, had ever been given to man. By the aid of this wonderful instrument we see now, clearly and brightly, so many things that could only, in former ages, have been guessed at as vague probabilities, that we no longer hesitate in practice to act upon its teachings, so that it has become to us, not only a powerful aid to the science of our profession, but a powerful motive principle to our practical advancement also.

The same also may be said of our increased knowledge of electrical phenomena. In my carly days (I do not think I am doing any dishonour to my teacher when I say this), these phenomena would be best described as an "interesting chaos"; but, by the labours of Wheatstone, of Faraday, and of a multitude of other untiring workers, they too have been so mastered, and marshalled, and harnessed as steerls to the chariot of our profession, that we drive, by their aid, through paths that were absolutely unknown in former days. Our forcfathers beheld the nerves of the body with wonder and delight, as channels along which the "animal spirits" might flow to and fro between the system and the brain, but the microscope and the study of electrical science have given us not only a much clearer insight into their structure and arrangement, but have also thrown a flood of light upon their vital properties and functions.

And what the microscope has done for anatomy and in aid of physiology, the stethoscope, the ophthalmoscope, the laryngoscope, and a number of other instruments, have done for medicine. Diseases, formerly only guessed at by their general symptoms, are now recognised and understood with clearness, and are catechiserl so closely, and in such minute detail, by instruments of scientific precision, that it is scarcely possible for them to elurle the search of the intelligent physician. Who, fifty years ago, for instance, would have dreamed of looking into a patient's larynx in search of ulceration, or of warty growths, or obstructive diseases? or, who would have believed it possible that the fundus of the eye could be so illuminated and explored as to give us actual optical demonstration of the physiological condition of the brain, and of structural changes taking place in its interior?

With the stethoscope we are able to read, almost as plainly as if we could see them, changes which are taking place in the interior of the chest, and to gauge them so accurately that when, at last, fate does give us the opportunity to see them, we very generally find that there is little left in the way of information that sight could have added to our knowledge. And so with the delicate exploring trocars of the present day ; the exploring scoop ; the test-tube ; and such like appliances, the physician is enabled not only to ascertain the condition of internal parts, but to verify his reasonings upon phenomena arising out of otherwise hidden conditions.

And while medicine has been advancing with such sure and steady steps, surgery has not been standing still. In surgery our age may certainly lay claim to the loftiest achievements that have ever graced the annals of our science, and we may look with pardonable pride upon many a victory won from the old domain of the so-called "impossible".

First and foremost in the roll stands out the inestimable blessing of anasthesia. Even I am old enough to remember the time when a surgical operation was a terrible ordeal indeed, and such as you will now very rarely be called upon to witness; and when, aided only by the consummate bravery which agonised nature can summon to her aid when fighting for life, the sufferer braced his energies to pass unaided through the mental and bodily strain of the torture. Such, indeed, were trying times both for the surgeon and for his patient; and, when I recall some such scenes as I witnessed in my early days, I can find no words in which adequately to paint the change, or to sum up what shou'd be our gratitude to those brave and noble men who, fearless alike of the unknown dangers of the practice, and the obloquy attendant upon failure, yet, like the late Sir James Simpson, fought out the early battle of anxesthesia for the world, and carricd it, in the face of danger, prejudice, and fanaticism, triumphantly to victory. Lulled by the beneficent influence of the vapour of ether or chloroform into the more than insensibility of sleep, a patient now willingly resigns himself to that from which, in former times, the bare thought of the agony to be endured has often sufficed to deter the very bravest, and one thought only of danger remains to carry disquiet into his heart.

Now and then, but, in proportion to the frequency of its use, with wonderful rarity, an anxsthetic, as you know, acts fatally. Of this danger, and its risk, every one must take the responsibility on his own shoulders. So long as sound judgment is exercised in the selection of the anæsthetic for each case, and every possible care is taken in its administration, we fulfil all the duty that can reasomably be claimed of us; and, in my opinion, we should be as little justified in withholding chloroform from the thousands to whom it is perfectly safe, because it proves unsafe here and there to one, as we should in saying that railways must be abolished, because, now and then, some one of the many thousands who travel loses his life in an accident.

Next on the list comes the great surgical triumph of our age, the operation of ovariotomy, by the help of which, many sufferers who, in former years, were resigned without a struggle to their fate are now rescued, and restored to the enjoyment of perfect health. For years after its first introduction into England by Dr. Clay of Manchester, so great was the risk attending its performance supposed to be, and so uncertain the diagnosis of the cases in which it was thought to be admissible, that surgeons of all ranks united in condemning it as an unjustifiable proceeding. I myself have heard it denounced in unmeasured terms by one of the lcading surgeons of this town as a proceeding too cruel and barbarous eter to be admitted within the pale of legitimate surgery! and yet, with persevering bravery, such men as Clay, Spencer Wells, and Keith, have not only shown it to be a perfectly justifiable operation, but are able to point with pride to their records of hundreds upon hundreds of successful cases !

To ovariotomy may be added lithotrity as another of the triumphs of the age. A hundred years ago, nearly every sufferer for calculus was doomed, from the very commencement of his complaint, to a lingering 
and painful death. Only here and there a single surgeon could be found who would dare to operate for the relief of such cases; and equally few patients dared to submit to the operation. Then came a time when, the magnitude and growing frequency of the evil being urgent, the operation of lithotomy came to be more deeply studied, and more general, and finally took its place as one of the most brilliant achievements of surgery! But it remained for the surgeons of our own day to show that the disease may be eradicated by a more simple process, and that, by crushing the stone in situ, the sufferer may often be relieved with comparatively little risk, and with so little pain that he does not even need the aid of an anæsthetic.

In the resection of diseased joints where we should formerly have amputated limbs, in the freedom with which we venture to explore their cavities with the aspirator, in the manner in which, with the same instrument, we venture to unload the serous cavities of the body of the products of disease, not holding either the peritoneum or pericardium too sacred for our reforming energies, I might point to the advances of the surgery of our day; but I may not stay to dwell so much upon individual features in the picture I would paint for you as upon its broader outlines.

Amongst those broader outlines, there are two which stand out so prominently, that I cannot consistently pass them over without notice. We can scarcely, perhaps, claim for them that they are absolute novelties, for the objects at which the $y$ aim are of such manifestly great importance, that, so long as surgery has existed as an art, so long have men's minds been searching in their direction. But to their development and general application, we may fairly and legitimately lay claim as amongst the surgical advances of our time.

One of these is the attempt that has been made by means of the antiseptic method of dealing with wounds to render them as harmless as is possible. That we have succeeded in this as perfectly as we have in our endeavours, by means of anæesthetics, to render operations painless, we can hardly claim ; but that much has been done to lessen the dangers attendant upon certain of the gravest accidents and surgical complications we ever meet with, cannot be denied. To those of us who have been in the habit, for instance, of seeing much of serious compound fractures, and have noted the restraining influence of carbolic acid treatment upon the exhausting discharges which usually accompany such accidents, the gain, I think, will seem a very clear one. I myself am certain that, by its aid, I have saved many joints that must otherwise have perished; and, every now and then, $I$ am very proud when I receive a hearty grasp from a hand which, had it not been for antiseptic surgery, I feel sure I must have sacrificed. Then, again, the very appellation " antiseptic" points to another class of effects which should be of unspeakable value in the treatment of surgical ailments. Unfortunately, however, we shall still be compelled occasionally, notwithstanding all our care, to point out and explain to you the effects of septic influences on the body; and I fear it will be long ere you are deprived of the opportunity of studying the symptoms and treatment of such diseases as pyæmia, septicæmia, hospital gangrene, and such like. Nevertheless, though antiseptic surgery may not have accomplished all we could wish, nor, indeed, all that has been claimed for it by its advocates and supporters, it has done a great deal, and will carry the name of Joseph Lister, not only to the farthest ends of the civilised world, but to remote posterity, as one of the greatest of the many great conservative surgeons of the nineteenth century.

And, as we have succeeded in rendering our operations painless, and have made a bold stroke in the hope that we may render them as harmless as is consistent with the knowledge of our day, so also we have succeeded in rendering them, when we wish it, for the most part absolutely "bloodless". I do not say that it is always advisable to do this ; indeed, I would rather say distinctly that it is not; and yet there are so many delicate operations, in which the presence of blood in the wound, by obstructing our vision and marring the precision of our work, proves a serious drawback, that we hail with great satisfaction the power we now possess of rendering them " bloodless", at all events, at will.

And now, gentlemen, I think I have shown you that, if our colleagues the physicians are advancing with rapid strides, we surgeons have not been standing still; and it only remains to me to endeavour to point out, as far as I am able, the paths by which you, as a rising generation, may continue to carry on the banner of our profession to still greater and more ennobling victories.

We, of the generation of which I must call myself in some way a representative, must rest content with the laurels we have already won we have passed the summit of the hill of life, and some of us are nearing the level plains through which flows the great river on its onward way to the ocean of eternity; our eyes are growing dim, and our hands are becoming feeble; but you, who are rising to the ascent with all the energy and freshness of youth to give elasticity to your steps, woble work before you to do.

We, who are wearying with the fight, are preparing to hand on the banner to you, that you may carry it into new fields, may win new victories for it, and inscribe it with yet further triumphs; and, if you ask me whither or in what direction I would advise you to look, I would point to the regions of "preventive medicine".

In those regions, you will find an almost uncultivated field for your energies, and, as it has ever been more commendable to prevent than to cure evils, so, in proportion as you succeed, will your work be of greater interest and value. Consider for a moment how vastly more numerous are the illnesses which we are able to prevent than those which we are able to cure. How the thought brings to our minds at once such subjects as those of drainage and ventilation; of our watersupply ; of overcrowded dwellings, and especially of schools; of the manner in which, in these institutions, the brains of our children are often, in defiance of the very simplest laws of health, exhausted, whilst their bodies are immured in rooms charged with an atmosphere which is poison; of impure and unwholesome feeding; of ill-assorted marriages; of the spread of infectious and contagious diseases, which a little knowledge of the simplest kind would check : all of the most vital imnortance to you as the future guardians of the public health.

I think there can be no doubt that the two greatest evils which afflict society in the present day, and which lead to the most wiclely spread and devastating forms of disease, are "intemperance" and that other "social evil", which fastens upon the youth of our day with such cruel talons, and which stamps the life of its victims with such a withering curse, that its sting is felt, not only so long as the sufferer's own life shall last, but continues to live on in unabated, aye in tenfold, vigour in the blood of his children and of his children's children.

And what of intemperance? Can we, as a profession, do more than others to aid in checking the spread of this great national evil ? Is it possible for us, as a body, to exert any beneficial influence in arresting its progress? I think it is. Whose voice is likely to be so influential in a family as that of its truest friend, especially when speaking with authoritative warning?

Upon some of the elder members, perchance upon the father or even upon the mother, this dreadful vice may have fastened with a grasp which all our influence may be powerless to unclasp, and from such cases we can only retire disheartened, discomfited, and saddened; but to the younger members of the group we may still appeal with more of hope; to them our voices may still come home with deterrent power; and, if we can only assure them, not only upon grounds of morality, but can also show them, upon sound professional reasoning, that intemperance and comparatively early death are linked together with unfailing certainty, we may still do much to lessen the evil of such indiscriminate and thoughtless indulgence as may finally pass into confirmed and inveterate habits. I would ask you never to forget how easy it may be, by misdirected and unwise advice, to foster an indulgence, or to create a desire for that which unfortunately comes clothed with only too great a fascination.

Let me urge upon you, while you have the opportunity in the wards of the hospital, to note the effect of stimulants in every case in which they are prescribed. If you will do this, I venture to hope that, before you leave us, you will have learned their true value, and will haxe assigned them their proper places as medicines in the list of the arms with which you will go forth into the world to do battle with disease.

Many of us, in times past, have been, and some of us are still, accused of being too much in the habit of both recklessly prescribing stimulants and of fostering the idea that they form an essential part in our aliment; and it is against this teaching that I would warn you. That they are often of the greatest value, and to be replaced by no other remedies, I am quite ready to admit; that, without their aid, many a case now saved would sink hopelessly away, we can none of us deny. Ammonia, ether, and such like stimulants, are very good sometimes, and sometimes are even of greater value than wine or brandy; but to say that they can always take the place of these last is a doctrine against which all experience is emphatic; and this, I am sure, will come readily home in time to every one of you.

And what shall I say of that other evil I have ventured to name? Of how many frightful maladies would the world be rid if we could but put our heel on that hydra-headed monster "syphilis", and. stamp it out of existence! How many hundreds, aye thousands, of sufferers. would learn to bless our endeavours, if they only knew to what source rightly to attribute their ailments! How many of these ailments baffle our utmost skill! How many existences are made miserable from the cradle to the grave, and yet how easy it is for us to stretch out a helping hand in this direction ! 
By some far-seeing philanthropists, the Contagious Diseases Acts were promulgated as an antidote; but a cry of horror has been raised against such legislation throughout the land. You will hear these Acts condemned in terms of unmeasured hatred and denunciation; but, long before you leave us, you will have learned to look upon them as amongst the most powerful agencies for good in all the armoury of Public Medicine. Society has raised its voice in almost universal chorus against them, and a cry of shame and horror has swelled up through all the land concerning them; but it is raised in ignorance, and, though fostered from most worthy motives, needs only the light of a little knowledge, such as that to which your eyes will presently be opened, to dissipate the mists of fanaticism by which it is embittered, and to hush it to the silence of death. God forbid that I should seek to further any step that should tend to lessen the purity of English women ; but we know only too well how deeply changed is the nature of those to whom, and to whom alone, these Acts can apply, and how infinitely below all ordinary standards they have fallen; and surely we are bound by an inflexible chain of duty to endeavour by every means in our power, in the interest of those who are yet unborn, to check the spread of the illimitable evils which this vice is capable of inflicting upon society.

They who hold that the evils which men bring upon themselves by their sin should be justly borne by themselves, as their punishment, are undoubtedly right; but they have no knowledge-they can have no knowledge - of the dreadful ramifications of the evils it is here sought to check. They forget that the effects of the sins of the fathers are to be carried by even the third and fourth generations of their children and it is on behalf of these, the purely innocent, the yet unborn sufferers, that we should pledge ourselves to fight. You will see, during the term of your attendance at the hospital, how dreadfully common is the picture of little children brought into the world to pass through a long and weary martyrdom of miserable life; in whose eyes the light of heaven is never destined to shine; whose very forms and features are so hideously distorted as to render them a byword among their fellows; whose bones, diseased and rotten from their birth, can never assume even the common proportions of health; whose digestive organs are unable to deal with food of even the very simplest character ; whose days, as long as they live, will be days of misery, and their nights only prolongations of the wretchedness to which they have been doomed; and to whom, at last, even death will come as a welcome and long looked-for friend, the only friend who is able to release them from the unceasing misery they have been compelled to bear in retribution for the sins of others. Gentlemen, I grant you this is a dreadful picture ; but it is not overdrawn ; not a shadow has been painted into it that you will not see over and over again with a frequency well calculated to appal those who will take such things to heart.

And, lastly, as I have said, you will find great scope for your energies, and a wide field in which to cultivate the highest usefulness of your profession, in tracking infectious diseases to their source, and in devising and elaborating the means by which they may not only be temporarily abated, but may, in the end, be altogether removed from amongst us.

Let your thoughts rest for a few moments upon what has already been effected in this direction. Look back upon the history of some of the greatest of this class of scourges. There was a time when, year by year, the whole earth was decimated by small-pox, and no human being was ever safe from its ravages; and where is that pestilence now? Buried in the grave of Jenner, or only rising up from time to time, a feeble shadow of its former self, to remind us of our want of watchfulness, our ignorance, or our fanaticism. Where is the old endemic plague of ague, which was wont, in years gone by, to lay so heavy a tax upon the population of our low-lying districts? Gone, under the system of drainage with which advancing science has taught us to unload the soil of its superfluous water charged with the products of decaying vegetation. There was a time when the plague and cholera were our regular periodical visitors, and when the whole community was left unguarded from the consequences of their dreadful visits. Or the former we hear comparatively little now; and the latter, though still unvanquished, and falling upon us from time to time with un abated virulence and too dreadful slaughter, is so much better understood now than it was in former years, that it is rarely permitted to reach us in its old epidemic form. Guarded by the wonderful power of the electric wire, no sooner does an outbreak happen in any region of the world, than every other part of it is so warned that it is up in arms to isolate it and prevent its further spread. Tracked in its origin at home to a foul or polluted water-supply, the whole deadly current may, if we so will it, be cut off at once; and our wells and springs may be so well guarded that, with reasonable care, the enemy can scarcely effect a lodgment in them; and so; to a great extent at any rate, we hold this pestilence too at arm's length.
But how about typhoid fever, diphtheria, scarlet fever, and a host of other septic and zymotic diseases? Are they not still so rife amongst us as to remain a standing and a lasting stain upon the medical knowledge of our day? Are they incapable of eradication? or are we ignorant of the sources whence they come? We know that they are the results of decaying animal matter, and yet we so dispose of our sewage that scarcely a stream in the land remains unpoisoned by it. Are we not, moreover, year by year, so saturating our soil with impurities of every kind, that a pure and uncontaminated spring must, ere long, become not only a rarity, but almost an impossibility?

Do we not shun, and that most wisely, the presence of those afflicted with infectious diseases so long as they remain amongst us; and yet, no sooner are they removed by death, than we are content, with tender sympathy indeed, and most loving care it is true (but with how much wisdom?), to lay them in the ground that they may slowly dissipate their terribly infectious gases through the soil, and saturating that, may thereby recharge the rains of heaven, as they filter through it, with all their virulence and terrible power of reproduction, in the systems of the living. I am not the thorough and entire believer in the disinfecting and depurating power of the soil that I once was; for terrible examples of its failure have, in my judgment, come under my notice.

Sir Henry Thompson has lately sounded a note of alarm on this subject; and though, for the present, it may fall upon ears unheeding or unsympathetic, I yet venture to think that, in time to come, his warning will be enforced by stern necessity, and that some better method of disposing of our dead will take the place of the burial so honoured and revered by us.

That cremation would succeed in protecting the living from many of the evils which, of necessity, result from the slow and ghastly decomposition of the dead who moulder in the grave I cannot doubt; but many years, I fear, must elapse before the public mind can be prepared for so great a change. It is impracticable, say some. Where, then, is the engineering science of our day? It is unholy, say others; but wherein consists the unholiness? What can it matter whether the body be destroyed in an hour or in twenty years? Destroyed it must be at last, and reduced to its simplest elements; and whether in the bosom of the earth, in the trackless paths of the ocean, or in the fiery flame of the purifying furnace, can matter little, so only that it rests " in sure and certain hope of a joyful resurrection".

\section{N 0 T E S}

OF

\section{EX PERIENCES I N E GYPT.}

BY W. H. FLOWER, F.R.S.,

Hunterian Professor of Compurative Anatomy in the Royal College of Surgeons of England, etc.

\section{IV.-The Nule Voyage.}

FEw English who pass a winter in Egypt are content to remain the whole time at Cairo. The interest that has been awakened in the ancient history of the country must naturally make every one anxious to see the still remaining evidences of the wonderful civilisation of the Nile valley three thousand and more years ago. Almost every trace of the mighty cities built in the delta in Pharaonic times has disappeared. At Heliopolis, "the great Temple of the Sun, the high priest of which was father-in-law of Joseph, and, in later times, the teacher of Moses",* is now represented by a solitary obelisk standing, when we saw it, in a field of sugar-cane. Of the grandeur of Memphis, a single colossal statue of Rameses II lying on its face in a pool of water is all that remains. When the population of a district continues, and new towns rise up in the place of old ones, the fragments of the earlier structures are used up in their successors. This is a far easier process than digging fresh materials from the quarries. Thus Cairo has absorbed the remains of the great towns near which it was founded. Even the Pyramids were stripped of their outer casing stones to aid in the construction of the mosques of the Arab conquerors of Egypt, though the mountainous

* By far the most truthful, graphic, as well as poetical, descriptions of Egyptian scenery, are those by the Dean of Westininster, in the introductory chapters of his Sinai and Palestine, 2 work which no traveller in the East should be without. To obtain a knowledge of the customs of the people, ancient and modern, the standard works of Wilkinson and Lane are indispensable. Among numerous recent books, Zincke's Egypt of the Pharaols and the Khedive may be mentioned as containing interesting and original sketches of the condition of the country and inhabitants and Mariette Bey's Itineraire, and Apercu de l'Histoire d'Egypte, which may be obtained at the Museum of Antiquities at Cairo for five francs each, will be found most useful travelling companions. 